NASA/TM-2002-211286

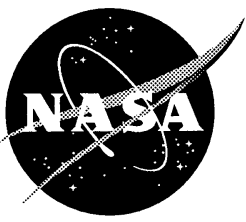

\title{
Fidelity of the Integrated Force Method Solution
}

Dale Hopkins, Gary Halford, and Rula Coroneos

Glenn Research Center, Cleveland, Ohio

Surya Patnaik

Ohio Aerospace Institute, Brook Park, Ohio 
Since its founding, NASA has been dedicated to the advancement of aeronautics and space science. The NASA Scientific and Technical Information (STI) Program Office plays a key part in helping NASA maintain this important role.

The NASA STI Program Office is operated by Langley Research Center, the Lead Center for NASA's scientific and technical information. The NASA STI Program Office provides access to the NASA STI Database, the largest collection of aeronautical and space science STI in the world. The Program Office is also NASA's institutional mechanism for disseminating the results of its research and development activities. These results are published by NASA in the NASA STI Report Series, which includes the following report types:

- TECHNICAL PUBLICATION. Reports of completed research or a major significant phase of research that present the results of NASA programs and include extensive data or theoretical analysis. Includes compilations of significant scientific and technical data and information deemed to be of continuing reference value. NASA's counterpart of peerreviewed formal professional papers but has less stringent limitations on manuscript length and extent of graphic presentations.

- TECHNICAL MEMORANDUM. Scientific and technical findings that are preliminary or of specialized interest, e.g., quick release reports, working papers, and bibliographies that contain minimal annotation. Does not contain extensive analysis.

- CONTRACTOR REPORT. Scientific and technical findings by NASA-sponsored contractors and grantees.
- CONFERENCE PUBLICATION. Collected papers from scientific and technical conferences, symposia, seminars, or other meetings sponsored or cosponsored by NASA.

- SPECIAL PUBLICATION. Scientific, technical, or historical information from NASA programs, projects, and missions, often concerned with subjects having substantial public interest.

- TECHNICAL TRANSLATION. Englishlanguage translations of foreign scientific and technical material pertinent to NASA's mission.

Specialized services that complement the STI Program Office's diverse offerings include creating custom thesauri, building customized data bases, organizing and publishing research results ... even providing videos.

For more information about the NASA STI Program Office, see the following:

- Access the NASA STI Program Home Page at http://www.sti.nasa.gov

- E-mail your question via the Internet to help@sti.nasa.gov

- Fax your question to the NASA Access Help Desk at 301-621-0134

- Telephone the NASA Access Help Desk at 301-621-0390

- Write to:

NASA Access Help Desk

NASA Center for AeroSpace Information 7121 Standard Drive

Hanover, MD 21076 
NASA/TM-2002-211286

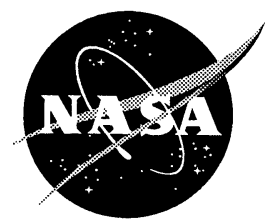

\section{Fidelity of the Integrated Force Method Solution}

Dale Hopkins, Gary Halford, and Rula Coroneos

Glenn Research Center, Cleveland, Ohio

Surya Patnaik

Ohio Aerospace Institute, Brook Park, Ohio

National Aeronautics and

Space Administration

Glenn Research Center

January 2002 
This report is a formal draft or working paper, intended to solicit comments and ideas from a technical peer group.

Trade names or manufacturers' names are used in this report for identification only. This usage does not constitute an official endorsement, either expressed or implied, by the National Aeronautics and Space Administration.

Available from

NASA Center for Aerospace Information 7121 Standard Drive

Hanover, MD 21076
National Technical Information Service 5285 Port Royal Road Springfield, VA 22100 


\title{
FIDELITY OF THE INTEGRATED FORCE METHOD SOLUTION
}

\author{
Dale Hopkins, Gary Halford and Rula Coroneos \\ National Aeronautics and Space Administration \\ Glenn Research Center \\ Cleveland, Ohio 44135
}

Surya Patnaik

Ohio Aerospace Institute

Brook Park, Ohio 44142

The theory of strain compatibility of the solid mechanics discipline was incomplete since St. Venant's 'strain formulation' in 1876. We have addressed the compatibility conditions for both the continuum $^{1}$ and the discrete system. ${ }^{2}$ This has lead to the formulation of the Integrated Force Method for finite element analysis ${ }^{3}$ and the Completed Beltrami-Michell's formulation in elasticity. ${ }^{4}$ IFM is easily specialized to obtain the existing methods. ${ }^{5}$ The reverse course cannot be followed. For example, the stiffness method cannot be specialized to obtain IFM because the stiffness method formulation is based only on the information contained in three quarters of the pie chart, see figure 1. The IFM variational functional yields the boundary compatibility conditions that were missed since $1876 .^{6,7}$ The compatibility limitation while blocking the growth of the primal method caused a bifurcation into the stiffness method and the redundant force method as sketched in figure 1 . The compatibility compliance by the stiffness method- attempted through mesh refinement—-may not be achieved for difficult problems. The classical force method with 'cuts' and redundancy is cumbersome. A Dual Integrated Force Method with displacements as the primal variable has also been formulated. IFM and IFMD yield identical solutions. A stiffness method code with a small programming effort can be improved to reap many IFM benefits when implemented with the IFMD elements.

A modest finite element code (IFM/Analyzers) based on the IFM theory has been developed. This code uses numerical integration but does not use reduced integration or bubble function techniques. For a set of standard test problems the IFM results were compared with the stiffness method solutions and the MSC/Nastran code in a controlled environment. ${ }^{7,8}$ For the problems IFM outperformed the existing methods, overshadowing the simplicity of the IFM elements. Superior IFM performance is attributed to simultaneous compliance of the equilibrium equation and compatibility condition. A method may be fallible but a utilization of the compatibility concept can never hurt. The additional information on compatibility condition has benefited analysis, ${ }^{7,8}$ structural design ${ }^{9}$ and optimization. ${ }^{10}$

Mr. Bob Harder of MSC/Nastran organization wrote to us expressing reluctance to accept the high fidelity IFM solutions. ${ }^{11}$ He wrote:

"Authors ... make wrong statements about the accuracy of MSC/NASTRAN in the paper."

We re-solved all the examples again. The versions of MSC/Nastran software used were: 70.7.0 Silicon graphics/IRIX64 6.5 (2001), 69.0 IBM/RISC System/6000 (1997), and MSC/Nastran 1982, Section 2.2 (1982, Ref. 12).

No numerical inaccuracy was detected in any of the seven tables in the paper. ${ }^{5}$ The exercise reconfirmed IFM performance for static and frequency analysis. A report was sent to Mr. Harder. ${ }^{13} \mathrm{We}$ did not receive a reply. 
Dr. Halford conducted a peer-review on IFM and the response received is given reference 14. Under his guidance a website (http://sdwww.grc.nasa.gov/patnaik) ${ }^{15}$ is being developed. The site addresses solid mechanics problems of the strength of materials curriculum. A user can compare three methods (IFM, IFMD and the stiffness method) for internal force, reaction, displacement, and stress for modest problems that can be modeled by about 5000 equations. A numerical test-bed has been developed to validate the code. It contains the cantilever problem that was also solved earlier. ${ }^{7,8}$ This example uses the RC0405 IFM element with five force unknowns that support linear variation of normal stress $\left(\sigma_{\mathrm{x}}=\mathrm{c}_{1}\right.$ $+c_{2} y$ and $\left.\sigma_{y}=c_{3}+c_{4} x\right)$ and constant state of shear stress $\left(\tau=c_{5}\right)$. The results obtained for this problem are given in the table and graphed in figure 2. The earlier version of MSC/Nastran exhibited a residual error of 8.6 percent in the tip displacement of the beam (bottom insert in figure 2). But the solution from the current version of the MSC/Nastran code is identical to the IFM results (top insert in figure 2). The tip displacement and the diagonal terms of the matrix for IFMD, two versions of MSC/Nastran code and the standard stiffness method are given in the table for a two-element model. The current version of MSC/Nastran code has now produced numbers that are identical to the IFM/IFMD solution.
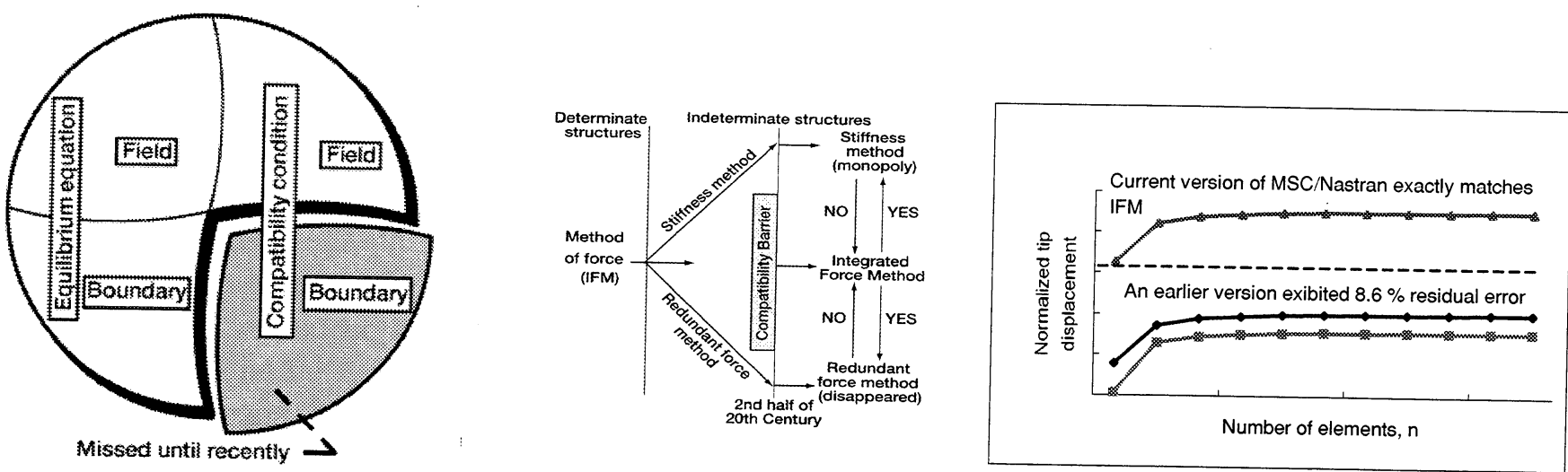

Figure 1.-Compatibility barrier prevented the development of IFM

Figure 2.-Solutions for a cantilever beam

\begin{tabular}{|c|c|c|c|c|}
\hline \multicolumn{5}{|c|}{ Solution to a two-element model } \\
\hline & IFM/IFMD & Stiffness Method & MSC/Nastran, 1990 & $\begin{array}{c}\text { MSC/Nastran, 2001 } \\
\text { (Identical to IFM/IFMD) }\end{array}$ \\
\hline Tip displacement in $10^{-3}$ in. & $\begin{array}{c}-1.1008 \\
\text { (Timoshenko:-1.152) } \\
\end{array}$ & 0.2576 & 1.0055 & -1.1008 \\
\hline & Normalized with $10^{6}$ & \multicolumn{3}{|c|}{ Normalized with respect to IFM/IFMD solution } \\
\hline $\begin{array}{l}\text { Diagonal coefficient of } \\
\text { governing matrix }\end{array}$ & 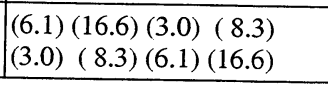 & \begin{tabular}{|l}
$(1.25)(1.03)(1.27)(1.04)$ \\
$(1.27)(1.04)(1.25)(1.03)$
\end{tabular} & $\begin{array}{l}(1.0)(1.02)(1.0)(1.01) \\
(1.0)(1.01)(1.0)(1.02)\end{array}$ & \begin{tabular}{|l}
$(1.0)(1.0)(1.0)(1.0)$ \\
$(1.0)(1.0)(1.0)(1.0)$
\end{tabular} \\
\hline
\end{tabular}

Industry recognizes the importance of analysis but research on new methods is not central to its worry because it is profit driven. It indeed has built magnificent structures in the past from the Great Wall of China to the Leaning tower of Pisa without the benefit of analysis. Industry will earn profit in the future even without investing in analysis methods. Industrial prosperity is directly linked to the economy of a society but has a superficially loose connection to the academic knowledge. Academia and research institutions, which traditionally researched the analysis methods, are becoming eager users of codes developed by few software houses. Because profit dictates the survival of the software business, it is unable to indulge in basic research. This conflict-in-interest stalemate situation can create a vacuum that may be very expensive to reverse, especially with the retirement of the experienced researchers. It is important to recognize that a solution to a solid mechanics problem is incorrect when it is compatibility 
non-compliant. The researchers in the field must adjust existing solutions and generate new ones that comply with the new conditions. The premier academic and research institutions should endeavor to increase the basic knowledge in the field to avoid saturation and arrest the declining solid mechanics discipline. The intent of this communication is to disseminate new knowledge on the compatibility concept to the structural mechanics community. It is not directed as a criticism to any individual or institution.

\section{REFERENCES}

1. Patnaik, S.N., "The Variational Energy Formulation for the Integrated Force Method," AIAA Journal, Vol. 24, No. 2, 1986, pp. 129-137.

2. Patnaik, S.N., Berke, L., and Gallagher, R.H., "Compatibility Conditions of Structural Mechanics for Finite Element Analysis," AIAA Journal, Vol. 29, May 1991, pp. 820-829.

3. Patnaik, S.N., Berke, L., and Gallagher, R.H., "Integrated Force Method Versus Displacement Method for Finite Element Analysis," Computers \& Structures, Vol. 38, No. 4, 1991, pp. 377-407.

4. Patnaik, S.N., Kaljevic, I., Hopkins, D.A., and Saigal, S., "Completed Beltrami-Michell Formulation for Analyzing Mixed Boundary Value Problems in Elasticity," AIAA Journal, Vol. 34, No. 1, 1996, pp. 143-148.

5. Patnaik, S.N., Coroneos, R.M., and Hopkins, D.A., "Dynamic Animation of Stress Modes via the Integrated Force Method of Structural Analysis," International Journal for Numerical Methods in Engineering, Vol. 40, 1997, pp. 2151-2169.

6. Patnaik, S.N., Coroneos, R.M., Hopkins, D.A., "Compatibility Conditions of Structural Mechanics," International Journal for Numerical Methods in Engineering, Vol. 47, pp. 685-704.

7. Patnaik, S.N. and Hopkins, D.A., "Stress Formulation in Three-Dimensional Elasticity," NASA/TP_2001-210515, Sept. 2001.

8. Patnaik, S.N., Hopkins, D.A., Aiello, R.A., and Berke, L., "Improved Accuracy for Finite Element Structural Analysis via an Integrated Force Method," Computers \& Structures, Vol. 45, No. 3, 1992, pp. 521-542.

9. Patnaik, S.N., Gendy, A.S., Berke, L., and Hopkins, D.A., "Modified Fully Utilized Design (MFUD) Method for Stress and Displacement Constraints," International Journal for Numerical Methods in Engineering, Vol. 41, 1998, pp. 1171-1194.

10. Patnaik, S.N., Guptill, J.D., Berke, L., "Singularity in Structural Optimization," International Journal for Numerical Methods in Engineering, Vol. 36, pp. 931-944.

11. Harder, R., MSC/Nastran Communications, (Aug. 1997).

12. Stress Recovery at Grid Points. MSC/Nastran Applications Manual, J.A. Joseph, ed., MacNealSchwendler Corporation, 1982, Section 2.2.

13. Hopkins, D.A., Technical Addendum to journal article IJNME 40:2151-2169 (1997).

14. Halford, G.R., Seven Reviews: Meek, J.L., Schmit, L.A., Przemieniecki, J.S., Thierauf, G., Miura, H., Belytschko, T., and Berke, L., (Jun. 1999).

15. Patnaik, S.N., IFM Web Site for Undergraduate Education-Under Construction, (2001).

16. MSC/NASTRAN Quick Reference Guide, Ver. 70.7.0, MacNeal-Schwendler Corporation, 1999.

17. Patnaik, S.N., and Hopkins, D.A., "Recent Advances in the Method of Forces: Integrated Force Method of Structural Analysis," Advances Engrg. Software, Vol. 29, No. 3-6, 1998, pp. 463-474.

18. Nagabhusanam, J., and Patnaik, S.N., "General Purpose Program to Generate Compatibility Matrix in the Integrated Force Method," AIAA Journal, Vol. 28, Oct. 1990, pp. 1838-1842.

19. Patnaik, S.N., and Joseph, K.T., "Generation of the Compatibility Matrix in the Integrated Force Method,” Comp. Meth. Appl. Mech. Eng., Vol. 55, No. 3, May 1986, pp. 239-257. 
20. Patnaik, S.N., and Joseph, K.T., "Compatibility Conditions From Deformation Displacement Relationship,” AIAA Journal, Vol. 23, Aug. 1985, pp. 1291-1293.

21. Patnaik, S.N., Hopkins, D.A., and Coroneos, R., "Structural Optimization With Approximate Sensitivities," Computers \& Structures, Vol. 58, No. 2, 1996, pp. 407-418.

22. Patnaik, S.N., "Analytical Initial Design for Structural Optimization via the Integrated Force Method," Computers \& Structures, Vol. 33, No. 1, 1989, pp. 265-268.

23. Patnaik, S.N., "Behaviour of Trusses With Stress and Displacement Constraints," Computers \& Structures, Vol. 22, No. 4, 1986, pp. 619-623.

24. Patnaik, S.N., and Gallagher, R.H., "Gradients of Behaviour Constraints and Reanalysis via the Integrated Force Method," International Journal for Numerical Methods in Engineering, Vol. 23, 1986, pp. 2205-2212.

25. Patnaik, S.N., and Yadagiri, S., "Design for Frequency by the Integrated Force Method," International Journal of Computer Methods in Applied Mechanics and Engineering, Vol. 16, No. 2, 1978, pp. 213-230.

26. Patnaik, S.N., and Dayaratnam, P., "Behaviour and Design of Pin-Connected Structures," International Journal for Numerical Methods in Engineering, Vol. 2, 1970, pp. 579-595.

27. Dayaratnam, P., and Patnaik, S.N., "Feasibility of Full Stress Design," AIAA Journal, Vol. 7, 1969, pp. 773-774.

28. Patnaik, S.N., and Satish, H.G., "Analysis of Continuum Using the Boundary Compatibility Conditions of Integrated Force Method," Computers \& Structures, Vol. 34, No. 2, 1990, pp. 287-295.

29. Vijayakumar, K., Krishna Murty, A.V., and Patnaik, S.N., “A Basis for the Analysis of Solid Continua Using the Integrated Force Method," AIAA Journal, Vol. 26, No. 15, 1988, pp. 628-629.

30. Patnaik, S.N., and Nagaraj, M.S., "Analysis of Continuum by the Integrated Force Method," Computers \& Structures, Vol. 26, No. 6, 1987, pp. 899-905.

31. Hopkins, D.A., Kaljevic, I., and Patnaik, S.N., "Constructing Finite Elements for the Integrated Force Method," NASA Tech Briefs, Vol. 21, No. 7, 1997, pp. 70-72.

32. Kaljevic, I., Patnaik, S.N., and Hopkins, D.A., "Treatment of Initial Deformations in the Integrated Force Method," International Journal of Computer Methods in Applied Mechanics and Engineering, Vol. 140, Nos. 3-4, 1997, pp. 281-289.

33. Kaljevic, I., Patnaik, S.N., and Hopkins, D.A., "Development of Finite Elements for TwoDimensional Structural Analysis Using the Integrated Force Method," Computers \& Structures, Vol. 59, No. 4, 1996, pp. 691-706.

34. Kaljevic, I., Patnaik, S.N., and Hopkins, D.A., "Three Dimensional Structural Analysis by the Integrated Force Method," Computers \& Structures, Vol. 58, No. 5, 1996, pp. 869-886.

35. Patnaik, S.N., "Integrated Force Method Versus the Standard Force Method," Computers \& Structures, Vol. 22, No. 2, 1986, pp. 151-163.

36. Patnaik, S.N., and Yadagiri, S., "Frequency Analysis of Structures by Integrated Force Method," Journal of Sound and Vibration, Vol. 83, 1982, pp. 93-109.

37. Patnaik, S.N., "An Integrated Force Method for Discrete Analysis," International Journal for Numerical Methods in Engineering, Vol. 6, No. 2, 1973, pp. 237-251.

38. Patnaik, S.N., Coroneos, R.M., and Hopkins, D.A., "Dynamic Analysis With Stress Mode Animation by the Integrated Force Method," NASA TM-4729, Apr. 1997. 


\section{APPENDIX A}

\section{RESPONSE TO MSC/NASTRAN}

\subsection{MSC/NASTRAN INQUIRY TO AUTHORS}

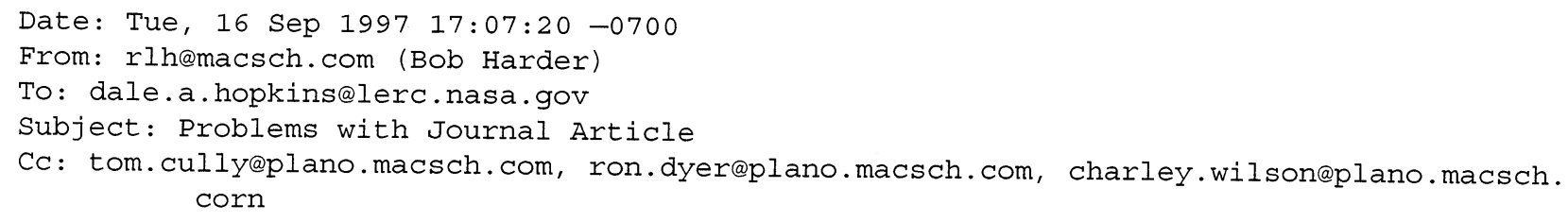

1. The data in the tables is must be incorrect. How can the frequencies for their "stiffness" method agree precisely in every case in Tables III, IV, and V with MSC/NASTRAN? It looks like it may be a transcription error. Table III shows MSC/NASTRAN results for the vibration frequency of an isotropic cantilevered beam. Their models CB_Model_2 and CB_Model_3 should both become MSC/NASTRAN HEXA8 with three elements, so how is it possible that MSC/NASTRAN gives such different results for these models? The frequencies given for MSC/NASTRAN do not agree with those found by MSC. Table III (frequency/beam theory) should be corrected as follows:

\begin{tabular}{|c|c|c|c|c|}
\hline \multirow[t]{2}{*}{ Elements } & \multirow{2}{*}{\multicolumn{2}{|c|}{$\begin{array}{l}\text { Result in paper } \\
\text { Model Mode } 3\end{array}$}} & \multicolumn{2}{|c|}{ MSC/NASTRAN } \\
\hline & & & Model & Mode 3 \\
\hline 6 HEXA8 & 1.637 & 1.640 & 1.0065 & 1.0419 \\
\hline HEXA 8 & 1.014 & 0.995 & 1.0221 & 1.2724 \\
\hline HEXA 8 & 2.672 & 1.862 & & \\
\hline 3 HEXA2O & 1.041 & 1.091 & 1.0322 & 1.01 \\
\hline 6 HEXA2O & not $r e$ & orted & 1.0137 & 0.9860 \\
\hline
\end{tabular}

It is not clear that the frequency should converge to beam theory. There are some corrections to consider. Higher order beam theory has transverse shear flexibility and rotary inertia, both of which will predict lower frequencies. The fully constrained root (not beam theory compatible) gives an added constraint which will produce higher frequencies. 
2. Table VII shows maximum vonMises stresses for a cantilever beam with a tip shear load. While MSC can not reproduce their numbers, I agree that their model will not get good answers. The reason is that they are using poor boundary conditions. In order to agree with beam theory, you must let a solid element model breathe at the constrained end. Using their coordinate system, you can constrain the $x-$ displacement, but the $y$ - and $z$-displacements should be constrained only in an average sense. This was done at MSC using an RBE3 element.

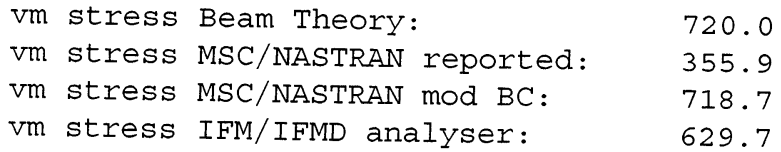

I conclude that with proper boundary conditions the MSC/NASTRAN I-\{EXA20 is better than the IFM/IFMD analyser.

3. Their analysis of the static deflection results in Table VII is based upon simple (Euler) beam theory. A better target value is based upon beam theory including transverse shear flexibility (Timoshenko)

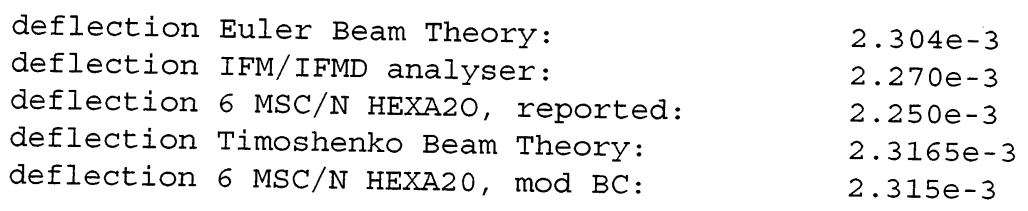

Using their boundary conditions, we agree that MSC/NASTRAN yields 2.25e-3, however with the correct boundary conditions MSC/NASTRAN is closer than the IFM/IFMD analyser. 


\subsection{HOPKINS RESPONSE TO MSC/NASTRAN}

X-Info: IDE / NASA Lewis Research Center

X-Sender: smdale @ popserve.lerc.nasa.gov

X-Mailer: Windows Eudora Pro Version 3.0.1 (32)

Date: Thu, 20 Nov 1997 10:09:12 -0500

To: rlh@macsch.com (Bob Harder)

From: Dale A Hopkins <Dale.A.Hopkins@lerc.nasa.gov>

Subject: Re: Problems with Journal Article

Cc: tom.cully@plano.macsch.com, ron.dyer@plano.macsch.com,

charley.wilson@plano.macsch.com

At 05:07 PM 9/16/97 -0700, you (Bob Harder) wrote:

TO: Surya Patniak, Rula Coroneos and Dale Hopkins

FROM: Bob Harder (MSC)

DATE: August 28, 1997

CC: Ron Dyer, Tom Cully, Charley Wilson

SUBJ: Problems with Journal Article

REF: DYNAMIC ANIMATION OF STRESS MODES VIA THE INTEGRATED FORCE

METHOD OF STRUCTURAL ANALYSIS. By Surya N. Patniak, Rula M.

Coroneos and Dale A. Hopkins. IJNME Vol. 40, pp. 2151-2168 (1997)

...[snipped]

TO: Bob Harder, MacNeal-Schwendler Corp.

FROM: Dale Hopkins, NASA/Lewis Research Center

CC: $\quad$ Ron Dyer, Tom Cully, Charley Wilson

RE: $\quad$ Addendum to Journal Article IJNME 40:2151-2169 (1997)

Dear Mr. Harder:

Thank you for your earlier e-mail correspondence regarding the above-referenced journal article. Attached to this e-mail is our reply in the form of a Technical Addendum which we will also submit to the publisher. If you are unable to open the attachment, which is a Microsoft Word for Windows 95 (Version 7.0a) document, I would be happy to mail or FAX it to you. I hope you will give us the benefit of the doubt that it was not our intention to give a negative portrayal of the MSC/Nastran product. In retrospect, I wish we had included the information contained in the Technical Addendum because I do feel it provides a more complete picture of the state-of-the-art and the proper place for our modest effort from an historical perspective on the development and evolution of finite element methods. If you would like to discuss this further, please do not hesitate to contact me again by e-mail or by telephone at 216-433-3260.

Sincerely,

\section{Dale Hopkins}

Dale A Hopkins

NASA/Lewis Research Center 21000 Brookpark Rd MS 49-8

Cleveland $\mathrm{OH}$ 44135-3191
Phone:216-433-3260

FAX: 216-977-7051

E-mail:Dale.A.Hopkins@lerc.nasa.gov 


\subsection{REPORT SUBMITTED TO MSC/NASTRAN}

"Dynamic Animation of Stress Modes via the Integrated Force Method of Structural Analysis"
IJNME 40:2151-2169 (1997)

The three issues raised by Bob Harder of MacNeal-Schwendler Corp. are specifically addressed in the three sections: Issue 1 - Typographical error in Table 3; Issue 2 - Results in Table 3; Issue 3 - Results in Table 7.

\section{Elements}

The elements available in the IFM/Analyzers code are standard elements with full integration schemes, i.e. with neither of the two advanced features available in MSC/Nastran elements: 1) reduced shear integration; nor 2) reduced shear integration with bubble function. Therefore, in the journal article the IFM results were compared with MSC/Nastran results obtained using elements without the advanced features.

We have now solved the problems with and without the advanced features of the MSC/Nastran elements. For the 8-node MSC/Nastran elements, the results are labeled as:

1. 8 -node standard isoparametric $(2 \times 2 \times 2$ integration)

2. 8 -node standard isoparametric $(3 \times 3 \times 3$ integration)

3. 8 -node reduced shear $(2 \times 2 \times 2$ integration)

4. 8-node reduced shear ( $3 \times 3 \times 3$ integration) 5. 8-node reduced shear with bubble function ( $2 \times 2 \times 2$ integration) $-\mathrm{MSC} / \mathrm{Nastran}$ default
element

The 8-node elements available in IFM/Analyzers (for the IFM and stiffness methods) use 2x2x2 standard isoparametric integration. These elements are comparable to the MSC/Nastran
element labeled as 1 above.

For the 20-node MSC/Nastran elements, the results are labeled as:

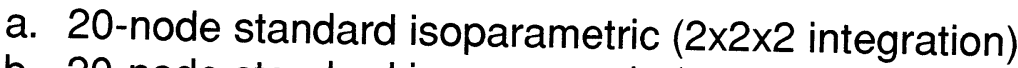

b. 20 -node standard isoparametric ( $3 \times 3 \times 3$ integration)

c. 20 -node reduced shear ( $2 \times 2 \times 2$ integration)

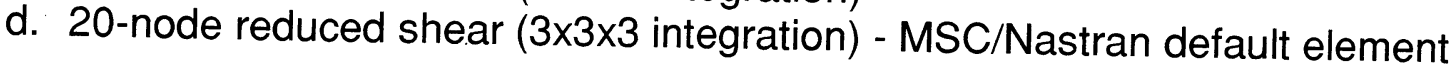

The 20-node elements available in IFM/Analyzers (for the IFM and stiffness methods) use $4 \times 4 \times 4$ and $3 \times 3 \times 3$ standard isoparametric integration, respectively. These elements are comparable to the MSC/Nastran element labeled as $b$ above.

\section{Boundary conditions}

Although the IFM/Analyzers code does not currently have provisions for interpolation constraint elements, nor for multi-point constraints, we have introduced another boundary condition to allow the model to "breathe" at the constrained end. This boundary condition, labeled as 
"clamped", is described as follows. For the model with 20-node elements, the displacement u (along the beam axis) is suppressed for all eight boundary nodes. The displacement $w$ (along the load direction) is specified to ensure symmetry about the $y$-axis in the yz-plane, by suppressing this component at nodes 13 and 14 as shown in Figure 1a. This boundary condition allows the beam to breathe along the z-direction. Likewise, the displacement $v$ (in the $y$-direction) is specified to ensure symmetry about the $z$-axis in the yz-plane, by suppressing this component at nodes 7 and 9 as shown in Figure 1a. This boundary condition allows the beam to breathe along the $y$-direction.

For the model with 8-node elements, the clamped boundary has the displacement u suppressed for all four boundary nodes. The displacement $w$ is suppressed at nodes 1 and 2 as shown in Figure $1 \mathrm{~d}$. This boundary condition allows the beam to breathe along the z-direction. Likewise, the displacement $v$ is suppressed at nodes 1 and 5 as shown in Figure 1d. This boundary condition allows the beam to breathe along the $y$-direction. The boundary condition used in the journal article, labeled as "rigid", suppresses all three displacement components for all nodes at the boundary (see Figures $1 \mathrm{~b}$ and $1 \mathrm{e}$ ).

At the tip of the beam, the $10 \mathrm{lb}$. load is distributed among the nodes of the models with 20-node and 8-node elements, as given in Figures $1 \mathrm{c}$ and 1f, respectively.

The beam theory results for the cantilever beam are provided, for reference, as follows:

- Maximum normal stress in $\mathrm{x}$-direction is 720 psi

- Tip displacement from Euler beam theory is $2.304 \times 10^{-3}$ in.

- Tip displacement from Timoshenko beam theory is $2.3165 \times 10^{-3} \mathrm{in}$.

- First frequency is $224.825 \mathrm{~Hz}$

- Third frequency is $1405.125 \mathrm{~Hz}$

\section{Issue 1 - Typographical error in Table 3}

Although Table 3, as submitted to the journal and as published in a NASA Technical Memorandum (Ref. 38), was correct, the published journal article contained the following typographical error. The first column, fourth row (associated with CB_Model_2) should have stated "Six/HX20_90" instead of "Three/HX08_90". We regret any confusion this may have caused.

\section{Issue 2 - Results in Table 3}

The frequency results for the problem with both three- and six-element models are given in expanded Table $3 \mathrm{a}$ and $3 \mathrm{~b}$. Both rigid and clamped boundary conditions are considered. The five 8-node elements of MSC/Nastran (1. - 5.) and the four 20-node elements of MSC/Nastran (a. - d.), as described earlier, are used along with 8- and 20-node IFM/IFMD and stiffness elements of IFM/Analyzers. 
- Eight-node elements: The MSC/Nastran results in Table 3 as published in the journal article are identical to the results obtained for MSC/Nastran 8-node element 1

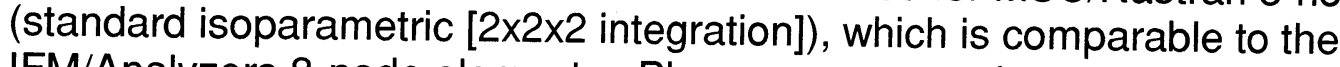
IFM/Analyzers 8-node elements. Please compare column 4, rows 1, 2, 5, and 6 in the published article with the MSC/Nastran element 1 results, given in columns 1,2, 5, and 6 in the expanded Table $3 b$.

- Twenty-node elements: The MSC/Nastran results in Table 3 as published in the journal article are identical to the results obtained for MSC/Nastran 20-node element b (standard isoparametric [ $3 \times 3 \times 3$ integration]), which is comparable to the IFM/Analyzers 20-node elements. Please compare column 4, rows 3, 4, 7, and 8 in the published article with MSC/Nastran element b results, columns $1,2,5$, and 6 in the expanded Table $3 a$.

- Frequencies: The IFM/IFMD frequency results are in agreement with the results obtained with MSC/Nastran advanced elements 5 (8-node reduced shear with bubble

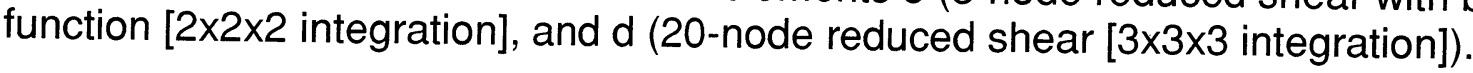

\section{Issue 3 - Results in Table 7}

The stress and displacement results for the problem with both three- and six-element models are given in an expanded Table 7 . Both rigid and clamped boundary conditions are considered. The four 20-node elements of MSC/Nastran (a. - d.), as described earlier, are used along with the 20-node elements of IFM/Analyzers.

- Stress Results: The normal stress in the $x$-direction calculated using the $\mathrm{MSC} /$ Nastran element $b$ (standard isoparametric [ $3 \times 3 \times 3$ integration]), which is comparable to the IFM/Analyzers elements, converged to 396.01 psi. for the 6element model with clamped boundary conditions. For the same conditions, the IFM/IFMD element produced a normal stress of 715.77 psi, while beam theory gives $720 \mathrm{psi}$. The results with the default (improved) MSC/Nastran element (with reduced shear [ $3 \times 3 \times 3$ integration]) and the IFM/IFMD element agree with beam theory results with minor deviations.

- Displacement Results: For the 6-element model with clamped boundary conditions, the displacement results agree with Timoshenko beam theory as follows:

- 1.0000 for Timoshenko beam theory

- 0.9869 for IFM/IFMD

- 0.9836 for MSC/Nastran element b

- 1.0006 for MSC/Nastran element d (default element)

- 0.9994 for MSC/Nastran element d with the RE3 constraint (the element referenced in the correspondence from MSC)

- Boundary Conditions: The improvement in displacement results between the rigid, clamped, and MSC's RE3 constraint boundary conditions for the 6-element, 20-node per element, model are as follows: 


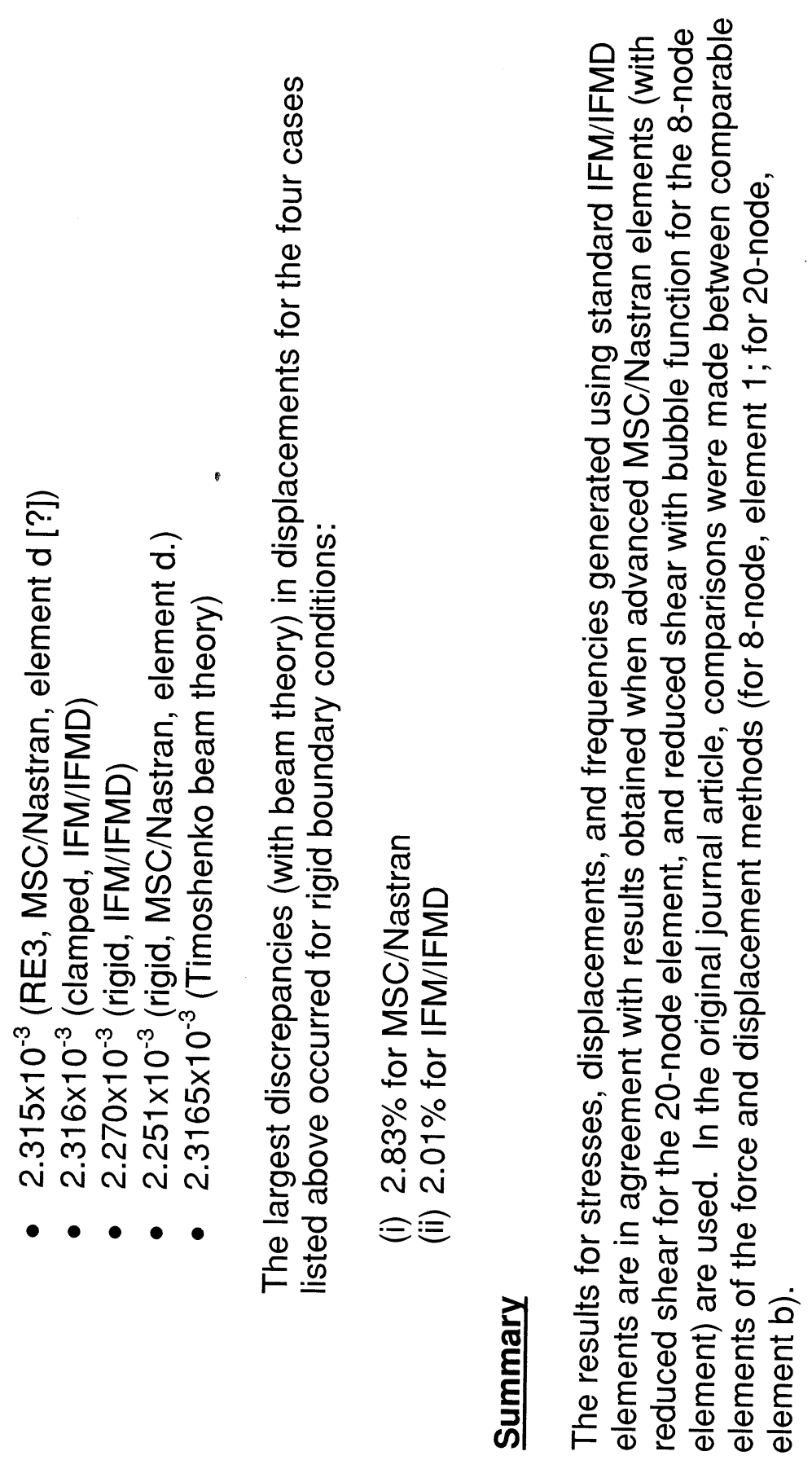




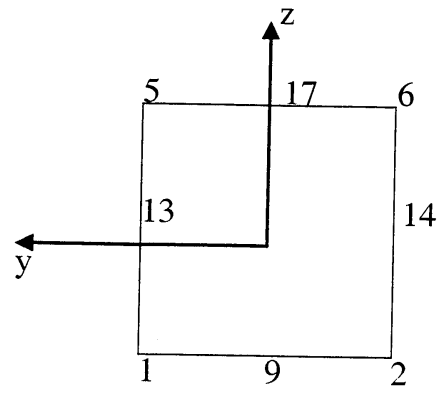

$\mathrm{u}=0$ at all 8 nodes

$\mathrm{v}=0$ at nodes $9 \& 17$

$\mathrm{w}=0$ at nodes $13 \& 14$

(a) Clamped boundary condition

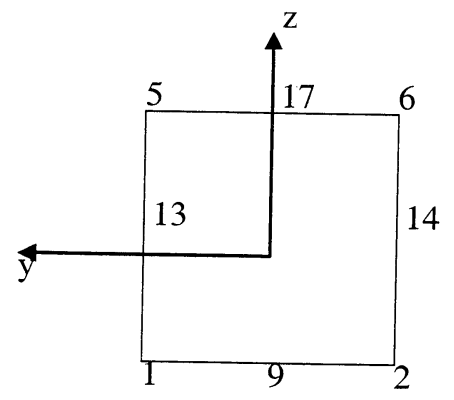

$\mathrm{u}=\mathrm{v}=\mathrm{w}=0$ at all 8 nodes

(b) Rigid boundary condition

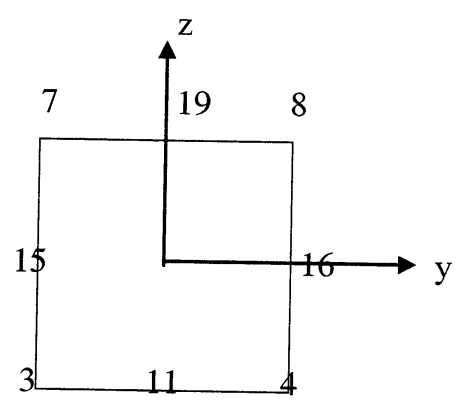

Load of (-7/6) $\mathrm{lb}$ at nodes $3,4,7$, and 8 Load of $4 \mathrm{lb}$ at nodes $15 \& 16$

Load of $10 / 3 \mathrm{lb}$ at nodes $11 \& 19$

(c) Load distribution

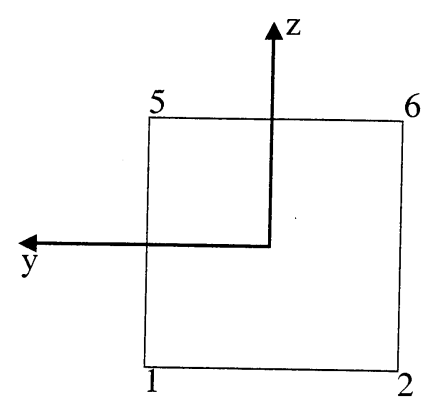

$\mathrm{u}=0$ at all 4 nodes

$\mathrm{v}=0$ at nodes $1 \& 5 \mathrm{y}$

$\mathrm{w}=0$ at nodes $1 \& 2$

(d) Clamped boundary condition

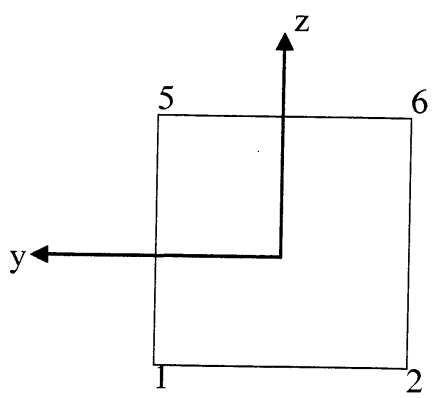

$\mathrm{u}=\mathrm{v}=\mathrm{w}=0$ at all 4 nodes

(e) Rigid boundary condition

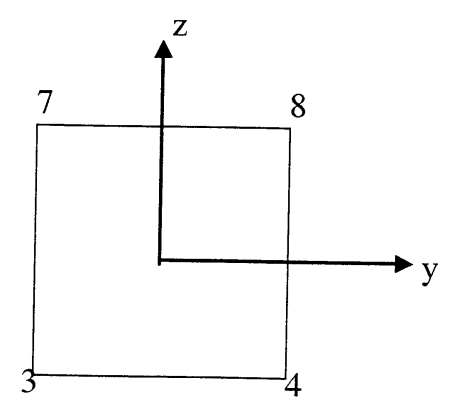

Load of $2.5 \mathrm{lb}$ at nodes $3,4,7$ and 8

(f) Load distribution

Figure A1. - Eight-node and twenty-node CHEXA elements with boundary conditions and load distributions. 
Expanded Table 3a (1st and 3rd mode frequency normalized with respect to beam theory solutions)

\begin{tabular}{|c|c|c|c|c|c|c|c|c|}
\hline & \multicolumn{4}{|c|}{ Six twenty-node element model (6HX20) } & \multicolumn{4}{|c|}{ Three twenty-node element model (3HX2O) } \\
\hline & \multicolumn{2}{|c|}{ Rigid boundary } & \multicolumn{2}{|c|}{ Clamped boundary } & \multicolumn{2}{|c|}{\begin{tabular}{|l|} 
Rigid boundary \\
\end{tabular}} & \multicolumn{2}{|c|}{ Clamped boundary } \\
\hline Methods & 1st mode & 3rd mode & 1st mode & 3rd mode & 1st mode & 3rd mode & 1st mode & 3rd mode \\
\hline IFM/IFMD & 1.007 & 0.983 & 0.993 & 0.968 & 1.025 & 1.070 & 1.004 & 1.038 \\
\hline Stiffness & 1.014 & 0.995 & 0.994 & 0.974 & 1.041 & 1.091 & 1.006 & 1.063 \\
\hline \multicolumn{9}{|c|}{ MSC/Nastran } \\
\hline a & * & * & * & * & $\star$ & * & * & * \\
\hline $\mathrm{b}$ & 1.014 & 0.995 & 0.994 & 0.974 & \begin{tabular}{l|l|}
1.041 \\
\end{tabular} & 1.091 & 1.006 & 1.063 \\
\hline$c$ & * & * & * & * & * & * & * & * \\
\hline$d$ & 1.013 & 0.988 & 0.993 & 0.965 & 1.031 & 1.016 & 0.993 & 0.976 \\
\hline
\end{tabular}

Expanded Table 3b (1st and 3rd mode frequency normalized with respect to beam theory solutions)

\begin{tabular}{|c|c|c|c|c|c|c|c|c|}
\hline & \multicolumn{4}{|c|}{ Six eight-node element model (6HX08) } & \multicolumn{4}{|c|}{ Three eight-node element model (3HX08) } \\
\hline & \multicolumn{2}{|c|}{ Rigid boundary } & \multicolumn{2}{|c|}{ Clamped boundary } & \multicolumn{2}{|c|}{ Rigid boundary } & \multicolumn{2}{|c|}{ Clamped boundary } \\
\hline Methods & 1st mode & 3rd mode & 1st mode & 3rd mode & 1st mode & 3rd mode & 1st mode & 3rd mode \\
\hline IFM/IFMD & 1.005 & 1.044 & 0.998 & 1.036 & 1.021 & 1.274 & 1.007 & 1.264 \\
\hline Stiffness & 1.637 & 1.640 & 1.627 & 1.628 & 2.672 & 1.862 & 2.661 & 1.854 \\
\hline \multicolumn{9}{|c|}{ MSC/Nastran } \\
\hline 1 & 1.637 & 1.640 & 1.627 & 1.628 & 2.672 & 1.862 & 2.661 & 1.854 \\
\hline 2 & 1.637 & 1.640 & 1.627 & 1.628 & 2.672 & 1.862 & 2.661 & 1.854 \\
\hline 3 & 1.064 & 1.103 & 1.046 & 1.088 & 1.090 & 1.358 & 1.058 & 1.337 \\
\hline 4 & 1.637 & 1.640 & 1.627 & 1.628 & 2.672 & 1.862 & 2.661 & 1.854 \\
\hline 5 & 1.005 & 1.044 & 0.998 & 1.036 & 1.021 & 1.274 & 1.007 & 1.264 \\
\hline
\end{tabular}


Expanded Table 7

\begin{tabular}{|c|c|c|c|c|c|c|c|c|c|c|c|c|}
\hline & \multicolumn{4}{|c|}{ Maximum Von_Mises stress in psi } & \multicolumn{4}{|c|}{ Stress $\sigma_{\mathrm{x}}$ at root $=720 \mathrm{psi}$} & \multicolumn{4}{|c|}{\begin{tabular}{|c|} 
Tip Displacement \\
Euler 2.304E-3 in.; Timoshenko $2.316 \mathrm{E}-3$ in.
\end{tabular}} \\
\hline & \multicolumn{2}{|c|}{ Rigid boundary } & \multicolumn{2}{|c|}{ Clamped boundary } & \multicolumn{2}{|c|}{ Rigid boundary } & \multicolumn{2}{|c|}{ Clamped boundary } & \multicolumn{2}{|c|}{ Rigid boundary } & \multicolumn{2}{|c|}{ Clamped boundary } \\
\hline Methods & $6 \mathrm{HX20}$ & $3 \mathrm{HX20}$ & $6 \mathrm{HX20}$ & $3 \mathrm{HX20}$ & $6 \mathrm{HX20}$ & $3 \mathrm{HX20}$ & $6 \mathrm{HX20}$ & $3 \mathrm{HX2O}$ & $6 \mathrm{HX20}$ & $3 \mathrm{HX20}$ & $6 \mathrm{HX20}$ & $3 \mathrm{HX20}$ \\
\hline IFM/IFMD & 629.7 & 573.1 & 713.1 & 677.5 & 757.6 & 721.4 & 715.8 & 679.4 & $2.270 \mathrm{E}-03$ & $2.214 \mathrm{E}-03$ & $2.316 \mathrm{E}-03$ & $2.286 \mathrm{E}-03$ \\
\hline Stiffness & & & & & & & & & $2.246 \mathrm{E}-03$ & $2.161 \mathrm{E}-03$ & $2.314 \mathrm{E}-03$ & $2.279 \mathrm{E}-03$ \\
\hline$a$ & $1.0 \mathrm{E}+06 \dagger$ & $1.9 \mathrm{E}+05 \dagger$ & $1.1 \mathrm{E}+06+$ & $2.4 \mathrm{E}+05 \mathrm{~T}$ & 799.0 & 820.8 & 719.7 & 721.0 & $1.405 \mathrm{E}-02$ & $4.583 \mathrm{E}-03$ & $1.451 \mathrm{E}-02$ & 5.289E-03 \\
\hline $\mathrm{b}$ & 355.2 & 289.2 & 399.4 & 366.3 & 404.3 & 381.3 & 396.0 & 362.3 & 2.246E-03 & $2.161 \mathrm{E}-03$ & 2.314E-03 & $2.279 \mathrm{E}-03$ \\
\hline c & * & $5.7 \mathrm{E}+17 \dagger$ & $7.5 \mathrm{E}+17 \mathrm{\dagger}$ & $2.8 \mathrm{E}+17 \dagger$ & * & $3.4 \mathrm{E}+16 \dagger$ & $2.5 \mathrm{E}+16 \dagger$ & $-5.0 \mathrm{E}+16 \dagger$ & * & $2.350 \mathrm{E}+09$ & $3.749 \mathrm{E}+09$ & $2.892 \mathrm{E}+09$ \\
\hline d & 642.7 & 520.9 & 725.2 & 722.8 & 774.9 & 778.6 & 719.1 & 719.6 & $2.251 \mathrm{E}-03$ & $2.192 \mathrm{E}-03$ & $2.318 \mathrm{E}-03$ & $2.318 \mathrm{E}-03$ \\
\hline
\end{tabular}

†High values 


\section{APPENDIX- 2}

\section{External Reviews on Finite Element Method for the $21^{\text {st }}$ Century}

A specific question was raised:

- 'Should we invest in an IFM based Finite Element Method Project? or

- You believe the stiffness method to be adequate even for the $21^{\text {st }}$ century.

\section{Excerpts from Reviews}

\begin{tabular}{|c|c|c|c|c|}
\hline $\begin{array}{l}\text { John Meek } \\
\text { Australia }\end{array}$ & $\begin{array}{l}\text { Lucien Schmit } \\
\text { USA }\end{array}$ & $\begin{array}{c}\text { John } \\
\text { Premieniecki } \\
\text { USA }\end{array}$ & $\begin{array}{l}\text { George Thierauf } \\
\text { Germany }\end{array}$ & $\begin{array}{l}\text { Hiro Miura } \\
\text { USA }\end{array}$ \\
\hline $\begin{array}{l}\text { "Stiffness } \\
\text { method has } \\
\text { reached the } \\
\text { plateau of } \\
\text { diminishing } \\
\text { return". } \\
\text { "Rough } \\
\text { (stiffness } \\
\text { method) .. } \\
\text { results taken as } \\
\text { gospel truth - } \\
\text { with religious } \\
\text { belief, which is } \\
\text { dangerous". } \\
\text { ".. full and } \\
\text { enthusiastic } \\
\text { support .. for } \\
\text { project.." }\end{array}$ & $\begin{array}{l}\text { ".. makes a } \\
\text { persuasive case } \\
\text { for further } \\
\text { development of } \\
\text { IFM .." } \\
\text { "..Displacement } \\
\text { methods to } \\
\text { have difficulty in } \\
\text { predicting } \\
\text { stresses } \\
\text { accurately.." } \\
\text { "..invest in } \\
\text { IFM.." } \\
\text { "..deserves high } \\
\text { praise and } \\
\text { respect.." }\end{array}$ & $\begin{array}{l}\text { "IFM should be } \\
\text { developed ..just } \\
\text { as NASTRAN } \\
\text { was developed } \\
\text { for } \\
\text { Displacement } \\
\text { method.." } \\
\text { " accuracy } \\
\text { arguments in } \\
\text { favor of IFM are } \\
\text { well known.." } \\
\text { "Bottom line.. } \\
\text { further research } \\
\text {.. should be } \\
\text { initiated by } \\
\text { NASA." }\end{array}$ & $\begin{array}{l}\text { "Fully agree with } \\
\text {.. advantages of } \\
\text { IFM" } \\
\text { "Support revival } \\
\text { of "natural" way of } \\
\text { computing } \\
\text { stress.." } \\
\text { "Plasticity: IFM } \\
\text { possesses } \\
\text { immense } \\
\text { advantages.." } \\
\text { "Optimization } \\
\text { and } \\
\text { decomposition } \\
\text { offers same } \\
\text { advantage as } \\
\text { plasticity." }\end{array}$ & $\begin{array}{l}\text { "..intrigued } \\
\text { by .. new } \\
\text { compatibility } \\
\text { equations.." } \\
\text { "Develop } \\
\text { IFM/FMD.. } \\
\text { Important to } \\
\text { solve } \\
1 \text { million } \\
\text { degrees of } \\
\text { freedom .. } \\
\text { problem." } \\
\text { "..New } \\
\text { frontier in } \\
\text { solid } \\
\text { mechanics.." } \\
\text { "..NASA to } \\
\text { support } \\
\text { prototype } \\
\text { code } \\
\text { development. } \\
\text { " }\end{array}$ \\
\hline
\end{tabular}


National Aeronautics and

Space Administration

John H. Glenn Research Center

Lewis Field

Cleveland, $\mathrm{OH} 44135-3191$

Re: Finite element method for the $21^{\text {st }}$ century.

Dear --,

As we know, only approximate stress solution can be obtained for the vast majority of structural mechanics problems. Thus the founding the fathers of this discipline preferred calculating stress by two competing methods; then ascertaining accuracy by comparing the two solutions. This simple reasoning is not currently applicable because only the displacement (or stiffness) method solution is available. Traditionally, accurate resolution of a stress state was not intrinsic to the stiffness method. Despite progress stress accuracy by the stiffness method cannot always be guaranteed.

In this context we wanted to examine the potential of the Integrated Force Method to become a possible alternate formulation to the stiffness method. Because of your comprehension of this field, we would like to receive your response to the question: Should we invest in an IFM based finite element method project, or do you believe the stiffness method to be adequate even for the $21^{\text {st }}$ century?

We request your kind opinion on this matter. We look forward to hear from you at the earliest possible time. Let me thank you in advance for your time and consideration.

Sincerely,

Gary R. Halford, Ph.D.

Senior Technologist

M.S. 49-7, NASA Glenn Research Center

21000 Brookpark Road, Cleveland, Ohio 44135

Phone: (216) 433-3265

E-mail: Gary.R.Halford@grc.nasa.gov

Enclosure: IFM report. 


\section{UNIVERSITY OF QUEENSLAND}

St.Lucia 4072

Queensland

Civil Engineering Department

Australia

Professor J.L Meek B.E. B.S. M.S. PHD.

President: Numerical Analysis Research Coorporation Pty. Ltd.

Tel: (617) 33651569 , or 33788423

Fax: (617) 33654161 , or 33788568

May 18, 1999

Email: e2meek@brolga.cc.uq.oz.au

ATTENTION:

Dr. Gary R. Halford

Senior Technologist

Your reference: Letter from Dr. Surya Patnaik

M.S. 49-8 NASA Glenn Research Center

21000 Brookpark Road

Cleveland, Ohio 44135

U.S.A

Dear Dr. Halford

\section{Re:Integrated Force Method}

Today I received a very interesting letter and document from Dr. Parniak on the Integrated Force Method Analyzer. The observation that the stiffness method has reached a plateau of diminishing returns is self evident to any who can look at the journal articles in an objective manner. The danger of the present situation is that results from rather rough finite element analyses are being taken to be gospel truth with a sense of almost religious belief. Thus if the integrated force method offers the possibility of a better description of the stress fields within a continuum then the method is worthy of development. Thus I give my full and enthusiastic support to the proposed research project and would like to be kept informed of its progress. Thank you for the opportunity for reviewing the project. With my very best wishes for its success, and with my very best regards,

Yours sincerely

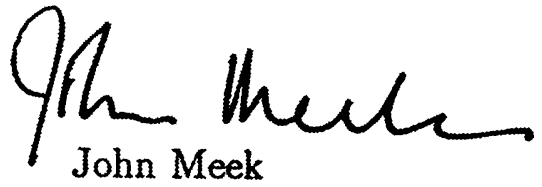

Professor Emeritus Civil Engineering 
545 Third Ave., S.

Edmonds, WA 98020

May 25, 1999

Dr. Gary R. Halford

Senior Technologist

NASA Glenn Research Center (M.S. 49-7)

21000 Brookpark Road

Cleveland, Ohio 44135

Dear Dr. Halford,

I am writing in response to your letter of May 5, 1999 regarding development of an "industrial strength IFM analyzer". While I have not done any significant finite element research for about 20 years, I find that the Presentation you sent me (entitled "Finite Element Method for the $21^{\text {st }}$ Century") makes a persuasive case for further development of the IFM in a finite element context.

Historically force methods were favored in Civil and Mechanical engineering applications involving very stiff structures. Accurate stress information was needed and displacements were often so small that they were often not even calculated. Also the classical redundant force method was an easy to visualize natural extension of the force method as applied to statically determinate structures.

In an aerospace context the stiffness method has long been favored because the structures to be analyzed are usually very flexible and they often involve finite elastic deflections, dynamic response, and elastic instability considerations. The displacement method (stiffness) of structural analysis has achieved a dominant position in aerospace structural analysis because is it well matched to the tasks that aerospace structural engineers generally face.

However, it is important to recognize that the commonly used displacement methods do have difficulty in predicting stresses accurately. In my opinion, aerospace structural analysis problems where stress accuracy is of paramount importance, can benefit from application of the IFM. It is hard to get around the fact that in the commonly used displacement methods, stresses must be determined by taking first or second derivatives of approximate displacements. These differentiations amplify the errors that exist in the approximate displacement solution.

In looking at various alternative methods in structural mechanics ( see copy of pl 4 from the Presentation you sent me ) it is useful to ask which equations of elasticity end up being satisfied approximately when a discretized solution is sought. For example, in the displacement method the equilibrium equations of elasticity are satisfied approximately. This follows from the fact that the equilibrium equations are satisfied "exactly" at only a finite number of mesh points (for purposes of this discussion I assume 
that the system displacements are truly single valued at all points). In the classical force method using stress functions (method 2 on p. 14, copy attached) it is the equations of compatibility that are satisfied approximately, because in a discrete formulation they are satisfied exactly at only a finite number of mesh points.

Let us now ask which equations of elasticity end up being satisfied approximately when a discrete solution is sought based on the CBMF (IFM). The answer appears to be that in a discrete formulation the equilibrium equations and the compatibility conditions (the $\mathrm{EE}$ and the $\mathrm{CC}$ ) are satisfied "exactly" at only a finite number of mesh points, therefore both the $E E$ and the $C C$ are satisfied approximately. Since the complete Beltrami-Michell Formulation is now available ( see attached copy of p. 13 from the Presentation ) as a set of partial differential equations expressed exclusively in terms of stresses, it would be interesting to seek a finite difference solution of the stress values at each mesh point. When this is done it would be best to use a test problem for which a closed form solution is available.

In any event the bottom line is that a discrete CBMF solution generates stress values( at a set of mesh points) directly, therefore the errors associated with differentiation of approximate displacement distributions are avoided. Furthermore, if strains or displacements are needed they can be obtained by back calculation (stresses $\rightarrow$ strains $\rightarrow$ displacements). The resulting strains and displacements will correspond exactly to the approximate stresses obtained via the discrete CBMF solution.

The IFM appears to be particularly well suited to stress analysis problems involving the introduction of concentrated loads, composite material internal and edge stress evaluation, and fatigue evaluations where stress accuracy is important. In the overall scheme of things I do not believe that the IFM will replace the current widely used displacement methods, but the IFM does seem to offer an essential new supplement to the currently available collection of tools for aerospace structural analysis.

In summary then, my answer to your basic question is YES, you should invest in an IFM finite element code project. However, it would be prudent to view the IFM finite element code as a high stress accuracy complement to existing displacement method programs, not a replacement for them. In closing I want to say that Dr. Patnaik deserves high praise and respect for successfully completing the Beltrami-Michell formulation in elasticity. This accomplishment has academic significance independent of any subsequently developed finite element analysis capability. deliberations.

I hope that you will find my observations and comments useful in your

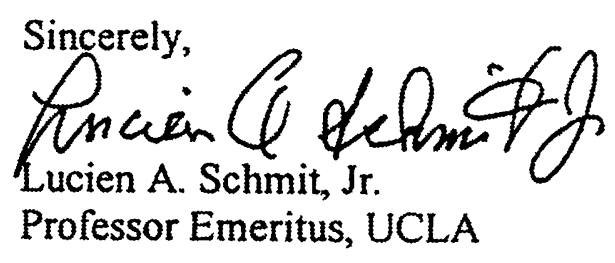




\section{Completed Beltrami-Michell Formulation in Elasticity}

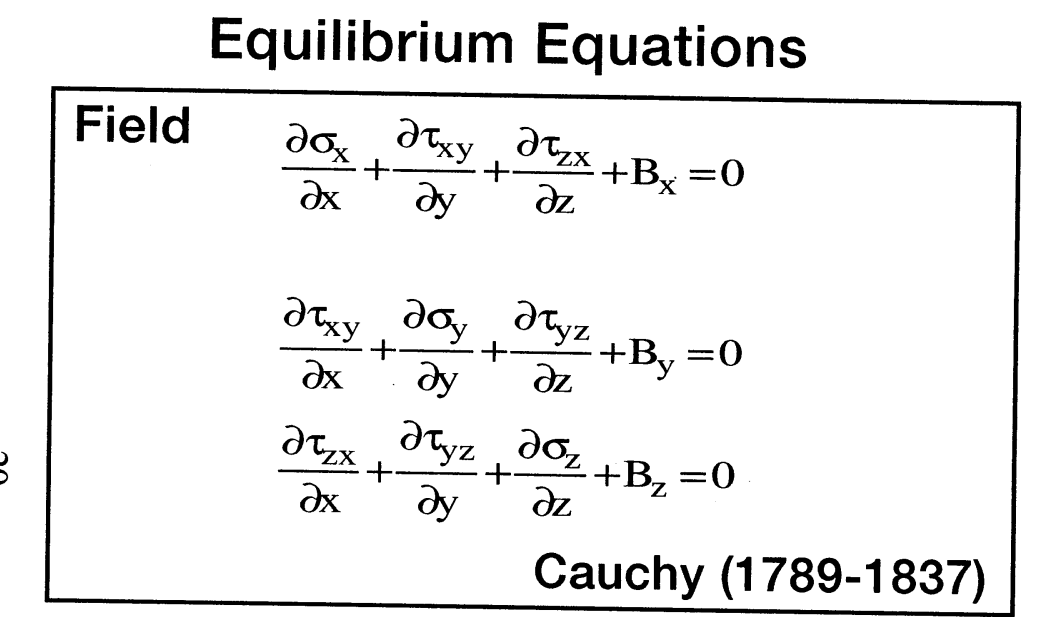

\section{Boundary}

$$
\begin{aligned}
& a_{v x} \sigma_{x}+a_{v y} \tau_{x y}+a_{v z} \tau_{x z}=\overline{P_{x}} \\
& a_{v x} \tau_{x y}+a_{v y} \sigma_{y}+a_{v z} \tau_{x z}=\overline{P_{y}} \\
& \tau_{x z} a_{v x}+\tau_{y z} a_{v y}+\sigma_{y} a_{v z}=\overline{P_{y}}
\end{aligned}
$$

Cauchy (1789-1837)

\section{Compatibility Conditions}

$$
\begin{aligned}
& \text { Field } \begin{array}{r}
\frac{\partial^{2}}{\partial z^{2}}\left(\sigma_{y}-v \sigma_{z}-v \sigma_{x}\right)+\frac{\partial^{2}}{\partial y^{2}}\left(\sigma_{z}-v \sigma_{x}-v \sigma_{y}\right)-2(1+v) \frac{\partial^{2} \tau_{y z}}{\partial y \partial z}=0 \\
\frac{\partial^{2}}{\partial x^{2}}\left(\sigma_{z}-v \sigma_{x}-v \sigma_{y}\right)+\frac{\partial^{2}}{\partial z^{2}}\left(\sigma_{x}-v \sigma_{y}-v \sigma_{z}\right)-2(1+v) \frac{\partial^{2} \tau_{z x}}{\partial z \partial x}=0 \\
\frac{\partial^{2}}{\partial y^{2}}\left(\sigma_{x}-v \sigma_{y}-v \sigma_{z}\right)+\frac{\partial^{2}}{\partial x^{2}}\left(\sigma_{y}-v \sigma_{z}-v \sigma_{x}\right)-2(1+v) \frac{\partial^{2} \tau_{x y}}{\partial x \partial y}=0 \\
\text { Saint-Venant (1797-1886) }
\end{array}
\end{aligned}
$$

$$
\begin{aligned}
& \text { Boundary } \\
& \frac{\partial}{\partial z}\left\{a_{v z}\left(\sigma_{y}-v \sigma_{z}-v \sigma_{x}\right)-a_{v y}(1+v) \tau_{y z}\right\}+\frac{\partial}{\partial y}\left\{a_{v y}\left(\sigma_{z}-v \sigma_{x}-v \sigma_{y}\right)-a_{v z}(1+v) \tau_{y z}\right\}=0 \\
& \frac{\partial}{\partial x}\left\{a_{v x}\left(\sigma_{z}-v \sigma_{x}-v \sigma_{y}\right)-a_{v z}(1+v) \tau_{z x}\right\}+\frac{\partial}{\partial z}\left\{a_{v z}\left(\sigma_{x}-v \sigma_{y}-v \sigma_{z}\right)-a_{v x}(1+v) \tau_{z x}\right\}=0 \\
& \frac{\partial}{\partial y}\left\{a_{v y}\left(\sigma_{x}-v \sigma_{y}-v \sigma_{z}\right)-a_{v x}(1+v) \tau_{x y}\right\}+\frac{\partial}{\partial x}\left\{a_{v x}\left(\sigma_{y}-v \sigma_{z}-v \sigma_{x}\right)-a_{v y}(1+v) \tau_{x y}\right\}=0 \\
& \text { Patnaik (1986-AIAA J) }
\end{aligned}
$$




\section{Methods of Structural Mechanics and Associated Variational Functionals}

\begin{tabular}{|c|c|c|c|c|c|}
\hline \multirow[b]{2}{*}{$\begin{array}{l}\text { Method } \\
\text { Number }\end{array}$} & \multicolumn{2}{|c|}{ Method } & \multicolumn{2}{|c|}{ Primary Variables } & \multirow[b]{2}{*}{$\begin{array}{l}\text { Variational } \\
\text { Functional }\end{array}$} \\
\hline & Elasticity & Structures & Elasticity & Structures & \\
\hline 1 & $\begin{array}{l}\text { Completed Beltrami-Michell } \\
\text { Formulation (CBMF) }\end{array}$ & $\begin{array}{l}\text { Integrated Force } \\
\text { Method (IFM) }\end{array}$ & Stresses & Forces & $\begin{array}{l}\text { IFM Variational } \\
\text { Functional }\end{array}$ \\
\hline 2 & Airy Formulation & $\begin{array}{l}\text { Redundant Force } \\
\text { Method }\end{array}$ & Stress Function & Redundants & $\begin{array}{l}\text { Complementary } \\
\text { Energy }\end{array}$ \\
\hline 3 & Navier Formulation (NF) & $\begin{array}{l}\text { Stiffness Method } \\
(\mathrm{DM})\end{array}$ & Displacements & Deflections & $\begin{array}{l}\text { Potential } \\
\text { Energy }\end{array}$ \\
\hline 4 & Hybrid Method (HF) & $\begin{array}{l}\text { Reissner Method } \\
\text { (RM) }\end{array}$ & $\begin{array}{l}\text { Stress \& } \\
\text { Displacements }\end{array}$ & $\begin{array}{l}\text { Forces \& } \\
\text { Deflections }\end{array}$ & Reissner \\
\hline 5 & Total Formulation (TF) & $\begin{array}{l}\text { Washizu Method } \\
\text { (WM) }\end{array}$ & $\begin{array}{l}\text { Stress, Strains \& } \\
\text { Displacements }\end{array}$ & $\begin{array}{l}\text { Forces, Deformations \& } \\
\text { Deflections }\end{array}$ & $\begin{array}{l}\text { Washizu } \\
\text { Functional }\end{array}$ \\
\hline
\end{tabular}

- Methods (2 to 5) have been derived from IFM equations 
Dr. Gary R. Halford

22 June 1999

Senior Technologist

MS 49-7, NASA Glenn Research Center

21000 Broadpark Road

Cleveland, OH 44135

Dear Dr. Halford:

I apologize for not responding earlier to the May 5, 1999 letter. I was away on a six week trip in Europe (England, Switzerland, and Poland where I received an honorary doctorate from the Warsaw University of Technology). I believe the proposal submitted by Dr. Patnaik merits support from NASA. Although the finite element methods originated from the Force Method, the competing Displacement Method quickly became the method of choice because of its simplicity. Today, because of the enormous computing capabilities available to us, there is no reason why the Force Method, or the generalized approach of the Integrated Force Method (IFM) should not be developed further and made available for structural analysis, just as NASTRAN was developed for the Displacement Method. The accuracy arguments in favor of IFM, presented by $\mathrm{Dr}$. Patnaik are well known. Thus my bottom line is that further research into the Force Method should be initiated by NASA.

You may find it interesting that in 1997, when I was a Visiting Professor with the University of Southern Florida (USF), I submitted a proposal dated 2 June 1997 to NASA Langley Research Center for the development of a general theory of the Force Method of analysis for aeronautical and space structures based on a new integrated formulation of equations of equilibrium and compatibility. The formulation of the governing equations was different from that of Dr. Patnaik, but the final results were the same. The proposal included a complete theoretical analysis and a pilot computer program, as a demonstrator. The total cost of under $\$ 100 \mathrm{~K}$ was to be shared between NASA $(70 \%)$ and USF $(30 \%)$. The proposal was turned down. It was argued that the state-of-the art of the commercial finite element analysis is such that the development of an alternative method could not be justified.

Sincerely yours

JBPrenteriecki

J. S. Przemieniecki. PhD, DSc

President

Astra Technologies, Inc. 


\section{Prof. Dr.-Ing. G. Thierauf \\ Baumechanik - Baustatik}

Prof. Or.tng. C. Thierauf Universităt GH Essen - Postfach $103764-45117$ Essen

Dr. Gary R. Halford

M.S. 49-7, NASA Glenn Research Center

21000 Brookpark Road

USA-Cleveland, OH 44135-3191

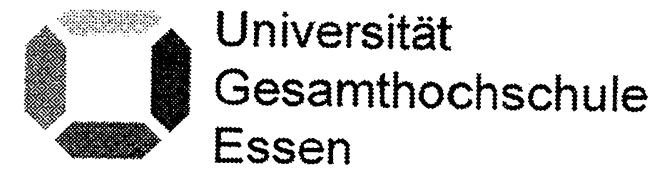

Fachbereich 10 Bauwesen

Universitätsstraße $15-045117$ Essen

\author{
Vermittlung: $\quad 10201 / 183.0$ \\ Direktwahl: $\quad(0201) 183-2670$ \\ Sekfetariat: $\quad(0201) 183-2672$ \\ Telefax: $\quad(0201) 183-2675$ \\ (intern: $\quad 0049 / 201183-2675$ ) \\ E-mail: $\quad$ th@bauwesen.uni-essen.de \\ g.thierauf@uni-essen.de \\ Raum: V15 S03 D23
}

Essen, 19.09.01 TH/pa

Dear Colleague,

for some reason, which I cannot trace exactly (it might well be my fault) I received your letter dated June 3rd only today together with a second letter from Gary R. Halford.

The question which you arise has directed much of my research for almost 10 years and I came up with the conclusion that we missed the train perhaps more than 30 years ago when the direct stiffness method started to dominate the force method. The very few researchers who went on working in the field of the force method and who contributed to the integrated force method (IFM) often had problems to justify their research. I fully agree with you with respect to the advantages of IFM and I would certainly support any attempt to find a revival of the ,natural way of computing stresses in structures.

From my experience I would like to mention two other most favourable aspects:

- Plasticity

The IFM possesses an immense advantage when dealing with all variants of plasticity. In this field, where general non-unique functional relations between stress and strain exist, the primal formulation does not only offer a one order increase in accuracy but also a tremendous saving in computational work,

- Optimization and decomposition

Early attempts to exploid the advantages of the IFM date back to the early sixties. As most of our constraints in structural optimization are governed by stresses, a direct stress-based formulation as in IFM offers the same advantages as in plasticity.

In addition, the IFM offers the possibility to generate an optimal vector basis for any iterative design. We have experimented with the basis generated by the compact eigenstresses and found out that we could overcome almost all the problems for decomposition in structural optimization.

Unfortunately our proposals for funded research found little resonance in the German Research Association - the experts were convinced that the diplacement formulation was superior. So I do hope that you will be more successful with your attempt and I can assure you that I would be prepared to support it as much as possible.

Sincerely,

Georg Thierauf

H:WorkarealFM REVIEWSIThierauf-Germany-11.doc 
National Aeronautics and Space Administration

Ames Research Center Moffett Field, California 94035

Repiy to Attn. of Mail Stop 237-11

Dr. Gary R. Halford

Senior Technologist

MS 49-7

NASA Glenn Research Center

21000 Brookpark, Cleveland, Ohio 44135
Hirokazu (Hiro) Miura

Aerospace Engineer

Mail Stop 237-11 Systems Analysis

NASA Ames Research Center

Moffett Field, CA 94-35-1000

Tel: (650) 604-5888

hmiura@mail.arc.nasa.gov

June 11, 1999

Dear Dr. Halford:

In his letter dated May 5th, 1999, Dr. Surya Patnaik requested me to convey my opinion on the merits of the Integrated Force Method as the subject of the future NASA research. I have been aware of IFM for some time and had a nice conversation with Dr. Patnaik on this subject when he visited Ames about a year ago for the CAS meeting. However, I have never studied technical details of IFM or IFMD in the past. This time, I would like to study this subject more meticulously, but my out of country trip during May 15 through 23 and an intensive proposal preparation activity from May 28 through June 4 th did not leave much time for me to do anything else. Since the deadline requested by Dr. Patnaik has passed already, I would summarize my impression on this subject in this letter.

I was very much intrigued by the derivation of a new compatibility equations to complete the Beltrami-Mitchell formulation based on the new variational function. I think it important to study the validity and implications of the content in the table summarizing five basic methods of structural mechanics from all the possible angles. Based on this table and the descriptions in the following articles, I interpreted that the contributions of IMF/IMFD in more detailed level may be identified as introduction of new compatibility equations in elasticity and the concept of working with "deformation variables" in structures. 
I believe that Dr. Patnaik's findings warrant systematic studies and developments to clarify a number of issues associated with IMF. Especially, basic theoretical aspects of IMF/IMFD in solid mechanics should be reviewed thoroughly, extended as required and documented in a self contained literature. On application side, we all know that commercial finite element structural analysis codes based on displacement methods have contributed a great deal to expand the horizon of structural analyses of structures of practical scale and complexity. Since these codes are now used as indispensable tools in the routine production environment, it will be difficult to change the way of doing business, unless very distinct advantages are found in the new approaches. However, there still exist such structures that cannot be analyzed satisfactorily or that are very difficult to create adequate analysis models within reasonable amount of effort.

It will be very appropriate for NASA to provide support for the basic theoretical study and comprehensive review of IMF/IMFD. Also, it will be appropriate for NASA to support prototype code development to the extent that performance of analysis program based on IMF/IMFD can be measured quantitatively on the modern computational infrastructure, to make fair assessments compared to the capabilities and performance of the analysis codes based on displacement methods.

In the following, I will try to list the subjects I thought of while reading the materials provided by Dr. Patnaik.

1. It will be helpful to formulate the weak form for finite element analysis based on the variational formulation of $\pi_{s}$ and to work out equivalence of strong and weak forms.

2. Explore the possibility of expanding IMF/IMFD to boundary element analysis of solids. Granted that I do not have any background in BE, but I am aware that the surface stress of solids obtained by straight-forward $\mathrm{BE}$ formulation is far from accurate, i.e. unusable in practice. On the other hand, some of the complex solid structure can only be modeled for analysis by $\mathrm{BE}$ codes based on the surface description available from CAD data. Can IMF/IMFD extend any help?

3. It is necessary to study basic characteristics and performances of the finite elements developed by IMF/IMFD. Especially, it will be very useful if accurate stresses can be obtained at the locations where stress gradients are large without using extremely fine mesh. Also, it is equally important to study the performance/robustness against element shape distortion from the ideal geometry.

4. In practice, a method that cannot be extended to deal with dynamics and problems in nonlinear regime may not be able to enjoy widespread acceptance. The results on natural frequencies of the turboprop blade reported in NASA TM 4729 are rather bizarre and such items must be studied very much in detail.

5. Design optimization capability is an increasingly important feature required for any structural analysis programs. In this context, it is important to perform 
research on feasibility of efficient sensitivity analysis scheme and on the development of good approximate models for key structural behaviors that maintain their accuracy for relatively large variations of values assigned to the design variables.

6. If the basic studies indicate promising trends for IFM/IFMD, it will become important to study the program architecture of the structural analysis code that implements IFM/IFMD from the viewpoint of handling very large scale problems. I consider it important to be able to solve problems with at least $1 \mathrm{M}$ degrees of freedom systems on a currently available computational platforms within reasonable resource requirements.

I would like to congratulate Dr. Patnaik and his coworkers for bringing up this innovative material from abstract idea to this stage to open up a new frontier in solid mechanics and possible development of new class of structural analysis capabilities.

Sincerely,

Signed

Hiro Miura 
Erom: "Les Berke" <lesberkeestratos.net>

To: <Gary.R.Halfordegrc.nasa.gov>

Subject: Patnaik's Program

Date: Wed, 23 Jun $199922: 26: 27-0400$

X-Mailer: Microsoft Outlook Express 5.00.2014.211

Dear Dr. Halford:

I got a lettex from Dr. Patnaik briefly describing his proposed long range program. The ideas go back to the very beginning of the developments of what became the Finite Element Technology. I had the good fortune to be present in the trenches zrom the very begining.

Before computers structural engineers were thinking only in terms of forces, force equilibriums, these were, and are the quantities against which to design a structure. These numbers were, and are directly obtainable from analysis methods refered to as the Force Method. Unfortunately in case of redundant structures the equilibrium equations had to be augmented by a set of equations to assure compatibility of deformations under the obtained forces. These equations were created by a very cumbersome method of somewhat arbitrary and non-unique "cuts" of the structure which then were "closed" by the augmenting equations.

Because of this complexity an other method won out for computer automation, but not without a struggle", in the mid sixties. You can always write the same number of equations in terms displacements as the number of displacement unkriowns in an axticulated structure or Einite Element Model. Unfortunately forces have to be obtained from strains that are derivative-like quantities being obtained as smali differences of large numbers, undercutting accuracy. The current remedy is to run inaccurate models to many digits of occuracy in an attempt to restore confidence in the results.

The significant contribution of Dr. Patnaik is that in his Integrated Force Method he was able to develop a consistent unique set of equations based on his "global" compatibility conditions instead of the arbitrary artifice of "cuts". This is a major and fundamental achievement that if available in the sixties, the Force Method would have been equally easy to automate, and would have won in that competition, forces being more direct and fundamental in an engineers mind. It is time to correct the past now that it is corractable.

Dr. Patnaik also derived fundamental compatibility boundary conditions in continuum mechanics, overlooked for a Century. These conditions also play a role in the development of finite elements of various classes for the Integrated Force Method.

In summary, being quite familiar with the related theories, the history of feM developments and the importance and timeliness of Dr. Patnaik's proposal I would like to highly recomend going ahead with his proposed developments. GlC could become a seminal source for a new technology in structural analysis that would eventually replace totally the current technology. Large investments are present in the current technology creating natural cesistence to replace it, but there is a well known statement having to do with a mouse trap...

Les Berke 


\begin{tabular}{lllllllllll}
\hline & $Y$ & $I$ & $V$ & $E$ & $R$ & $S$ & $I$ & $T$ & $Y$ \\
\hline
\end{tabular}

ROBERT R. WORORMICK SCHDOL OF

EVIVEERIVI; IVD APPLIES SCIENGE

Department of Merhanical Engineering

August 9, 1999

Gary R. Halford, Ph.D.

Senior Technologist

M.S. 49-7, NASA Glenn Research Center

21000 Brookpark Rd.

Cleveland, $\mathrm{OH} 44135$

Dear Dr. Halford:

Regarding your letter of May 5, I found the methodology interesting;

However, in view of the company competing needs, I cannot make any definitive statements about the need for IFM.

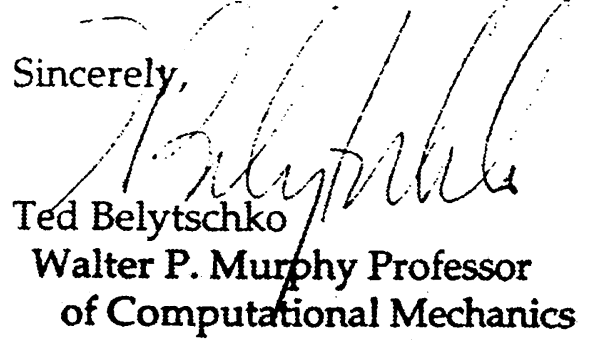



Public reporting burden for this collection of information is estimated to average 1 hour per response, including the time for reviewing instructions, searching existing data sources, collection of information, including suggestions for reducing this burden, to Washington of information. Send comments regarding this burden estimate or any other aspect of this Davis Highway, Suite 1204, Arlington, VA 22202-4302, and to the Office of Management and Budg Services, Directorate for Information Operations and Reports, 1215 Jefferson \begin{tabular}{l|l|l} 
1. AGENCY USE ONLY (Leave blank) & 2. REPORT DATE
\end{tabular}

4. TITLE AND SUBTITLE January 2002 3. REPORT TYPE AND DATES COVERED

Technical Memorandum

Fidelity of the Integrated Force Method Solution 6. AUTHOR(S)

WU-910-30-11-00

Dale Hopkins, Gary Halford, Rula Coroneos, and Surya Patnaik

7. PERFORMING ORGANIZATION NAME(S) AND ADDRESS(ES)

National Aeronautics and Space Administration

John H. Glenn Research Center at Lewis Field

Cleveland, Ohio 44135-3191

8. PERFORMING ORGANIZATION REPORT NUMBER

E-13087

9. SPONSORING/MONITORING AGENCY NAME(S) AND ADDRESS(ES)

National Aeronautics and Space Administration

Washington, DC 20546-0001

10. SPONSORING/MONITORING AGENCY REPORT NUMBER

NASA TM-2002-211286

11. SUPPLEMENTARY NOTES

Dale Hopkins, Gary Halford, and Rula Coroneos, NASA Glenn Research Center, and Surya Patnaik, Ohio Aerospace Institute, 22800 Cedar Point Road, Brook Park, Ohio 44142. Responsible person, Dale Hopkins, organization code 5930, 216-433-3260.

12a. DISTRIBUTION/AVAILABILITY STATEMENT

Unclassified - Unlimited

Subject Category: 39

Distribution: Nonstandard

Available electronically at http://gltrs.grc.nasa.gov/GLTRS

This publication is available from the NASA Center for AeroSpace Information, 301-621-0390.

13. ABSTRACT (Maximum 200 words)

The theory of strain compatibility of the solid mechanics discipline was incomplete since St. Venant's 'strain formulation' in 1876. We have addressed the compatibility condition both in the continuum and the discrete system. This has lead to the formulation of the Integrated Force Method. A dual Integrated Force Method with displacement as the primal variable has also been formulated. A modest finite element code (IFM/Analyzers) based on the IFM theory has been developed. For a set of standard test problems the IFM results were compared with the stiffness method solutions and the MSC/Nastran code. For the problems IFM outperformed the existing methods. Superior IFM performance is attributed to simultaneous compliance of equilibrium equation and compatibility condition. MSC/Nastran organization expressed reluctance to accept the high fidelity IFM solutions. This report discusses the solutions to the examples. No inaccuracy was detected in the IFM solutions. A stiffness method code with a small programming effort can be improved to reap the many IFM benefits when implemented with the IFMD elements. Dr. Halford conducted a peer-review on the Integrated Force Method. Reviewers' response is included.

\section{SUBJECT TERMS}

Solid mechanics; Compatibility conditions; Integrated force method (IFM); Stiffness method; IFM/Analyzer; MSC/Nastran; Reviews

\begin{tabular}{|c|c|}
\hline $\begin{array}{c}\text { 17. SECURITY CLASSIFICATION } \\
\text { OF REPORT }\end{array}$ & $\begin{array}{c}\text { 18. SECURITY CLASSIFICATION } \\
\text { OF THIS PAGE } \\
\text { Unclassified }\end{array}$ \\
Unclassified
\end{tabular}

19. SECURITY CLASSIFICATION OF ABSTRACT Unclassified
15. NUMBER OF PAGES 34

16. PRICE CODE

20. LIMITATION OF ABSTRACT 